\title{
A Comparative Study of Antioxidant Activities between Fresh and Dry Mushrooms in the Genera Cantharellus and Afrocantharellus from Tanzania
}

\author{
Donatha Damian Tibuhwa \\ Department of Molecular Biology and Biotechnology (MBB), University of Dar es Salaam, Dar es Salaam, Tanzania. \\ Email: dtibuhwa@yahoo.co.uk
}

Received November $20^{\text {th }}, 2013$; revised December $20^{\text {th }}, 2013$; accepted December $27^{\text {th }}, 2013$

Copyright (C) 2014 Donatha Damian Tibuhwa. This is an open access article distributed under the Creative Commons Attribution License, which permits unrestricted use, distribution, and reproduction in any medium, provided the original work is properly cited. In accordance of the Creative Commons Attribution License all Copyrights (C) 2014 are reserved for SCIRP and the owner of the intellectual property Donatha Damian Tibuhwa. All Copyright (C) 2014 are guarded by law and by SCIRP as a guardian.

\begin{abstract}
Cantharellus and Afrocantharellus mushrooms are widely consumed in both fresh and dry forms. However, their antioxidant and whether their values changing with drying processes are not known. This study establishes their values and the effect of sun drying on their quality and quantity. Methanolic extracts of five Cantharellus and two Afrocantharellus species were investigated. The investigation used (1,1-diphenyl-2-picrylhydrazyl radical) DPPH as a substrate to determine radical scavenging abilities. Further quantitative analyses for carotenoids, flavonoid, total phenolic compounds and vitamin C content were done using spectrophotometric assay at $515 \mathbf{~ n m}$. Comparatively, fresh mushroom had higher vitamin $C$ and Lycopene contents than their dry counterparts with $\beta$-carotene. Flavonoid and phenolic compounds were higher in dry forms than those in their fresh counterparts. Radical scavenging ability also varied with fresh forms depicting higher activity compared to dry forms. The variation was low in Afrocantharellus species ( $0.8 \%$ and $0.99 \%)$ while it was higher in Cantharellus species (24.12\% and $7.52 \%)$. The highest ability was observed in fresh forms of Cantharellus pseudocibarius $\left(\mathrm{EC}_{50}<0.14 \mathrm{mg} / \mathrm{ml}\right)$ while the least ability $\left(\mathrm{EC}_{50}=\mathbf{0 . 4} \mathrm{mg} / \mathrm{ml}\right)$ was from dry form of Cantharellus rufopunctatus. This shows that studied mushrooms are rich in antioxidants and their quality and quantities are affected differently in both forms. Both dry and fresh mushrooms are potential sources of natural antioxidants. The portrayed high scavenging ability by these mushrooms envisages promoting them into potential nutraceutics.
\end{abstract}

\section{KEYWORDS}

Antioxidant Activity; Fresh Mushrooms; Sun-Dried Mushrooms; Afrocantharellus; Cantharellus; 1,1-Diphenyl-2-picrylhydrazyl

\section{Introduction}

Antioxidants are chemical compounds that protect cells from damage by free radicals through inhibiting oxidation or reactions promoted by oxygen or peroxides. These free radicals are capable of damaging all components of body including proteins, lipids, DNA and sugars [1]. Antioxidants are thus important in living organisms because they may delay or stop formation of free radical by giving hydrogen atoms or scavenging them [2]. Oxidation reactions are essential to all aerobic organisms for energy production used in different biological processes.
Although all organisms are highly protected against oxidative damage by natural occurring antioxidant in our body such as glutathione created within cells, they are insufficient to totally prevent the damage. Uncontrolled reactions of production of oxygen reactive species lead to many pathophysiological disorders [3]. Many oxidative stresses, which lead to brain dysfunction, pathology of cancer, atherosclerosis, malaria and rheumatoid arthritis are also associated with cell damage caused by excess free radicals. Natural products that contain antioxidant property help to protect the endogenous system by scavenging the free radicals that play a major role in the 
progression of these wide ranges of pathological disturbances [1]. Synthetic antioxidants such as butylated hydroxytoluene-BHT, tertiary butylhydroquinone, esters of 3,4,5-trihydroxybenzoic acid and butylated hydroxyanisole-BHA, among others, have been tremendously resulting into potential toxicity in their applications [4]. This has stirred up an increased interest in the search and use of antioxidant rich food such as herbs, spices, seeds, cereals, fruits, vegetables and mushrooms $[5,6]$ in human diets for the interest of providing possible protective agents such as phenolic compounds that help human body reduce oxidative damage.

Polyphenols generally refer to complex groups of compounds with aromatic ring bearing hydroxyl group. They include complex structures such as flavonoids and anthocyanins as well as simple phenolic acids and derivatives. Polyphenols show chemopreventive, cytostatic, immunomodulatory, bacteriostatic/bactericidal, antifungal, anti-inflammatory, antioxidant and many other pharmacological activities [7]. Phenolic compounds have recently attracted much interest because in vitro and in vivo studies suggest that they have a variety of beneficial biological properties which may play an important role in the maintenance of human health [8]. The polyphenols are also well-known for their large array of biological actions that include metal chelation and enzyme modulation activities and free radical scavenging, among others $[9,10]$.

Mushrooms are known to have antioxidant activity [11-14]. They are also well-known for their rich sources of proteins, vitamins and minerals $[14,15]$. These properties have attracted a growing interest of using mushrooms in various nutraceutic products [16]. Mushrooms have also been reported as sources of physiological agents for medicinal applications and various therapeutic activities such as antioxidants, anti-carcinogenic, antiinflammatory, possessing antiviral, immune-enhancer and antibiotic among others [11,17-20]. In recent decades, various extracts of mushrooms and plants have increasingly demonstrated the potent and unique health enhancing properties of compounds and extracts of range of medicinal mushrooms. They are thus of great interest as sources of natural products thence highly studied, although, still there are several varieties of wild mushrooms whose nutritive and medicinal profiles have not been described especially from developing countries [21].

Tanzania is endowed with high diversified types of natural vegetations on different topology ranging from hilly mountains to low land grass, flat land and valleys which provide a highest diversity of indigenous wild mushrooms [22-27]. In the country, wild mushroom eating habit is more in rural areas and relies exclusively on collection from the wild, eating them fresh or sun-drying them for long preservation. Mushrooms from the genera Cantharellus and a recently new described genus Afrocantharellus [27], are among well-known and appreciated mushrooms collected mainly from miombo woodlands which form a part of estimated area of 2.7 million $\mathrm{km}^{2}$ on nutrient-poor soils in sub-Saharan Africa [28]. Some studies have confirmed that chanterelles are nutritious and rich sources of fat, carbohydrates, fiber and energy [29,30], but antioxidant properties of such wild mushrooms are still limited. For example, antioxidant of four Cantharelllus species has been reported from Himalaya and India $[31,32]$ where the species $C$. fries was found to have the highest antioxidant among the three studied taxa in Himalaya.

To the best knowledge of this study, there is no study which has been done to explore and establish the antioxidant activity and other medicinal properties of these well-eaten mushrooms in many communities mainly living near the miombo woodlands in Tanzania. Therefore, this work is aimed at establishing the antioxidant potential from twenty methanolic extracts of mushroom fruiting bodies of seven species in the genera Cantharellus and Afrocantharellus naturally growing symbiotically with miombo trees in different geographic locations of Tanzania. The work also establishes if the antioxidant and free radical scavenging activities values change with sun drying process which is the common preservation method used in the studied area.

\section{Materials and Methods}

\subsection{Sample Collection}

Mushroom samples were collected from different field sites in Tanzania (Figure 1). The collected mushrooms were identified using colored field guidebooks and monographs [22,23,33-35] and internet facility. Following fresh observation, some of the mushrooms were immediately frozen in deep freezer until further analysis while some were sun dried and deposited at the (DSM) University of Dar es Salaam herbarium and some duplicated at the Uppsala university herbarium (UPS). All details of the studied taxa are summarized in Table 1 and accompanying field photo in Figure 2.

\subsection{Quantitative and Qualitative Determination of Antioxidant Activity}

All the chemicals used in this work were analytical grade and purchased from Sigma Aldrich Co. (St Louis, MO, USA). The antioxidant ability of each species was analyzed using DPPH radical and antioxidant properties were analysed by determining the polyphenols (total 
Table 1. Details of the studied taxa.

\begin{tabular}{|c|c|c|c|c|c|}
\hline No & Species & Voucher & Locality in TANZANIA & Collection/herbarium number & GPS \\
\hline 1. & Afrocantharellus splendens & DDT153 & Kigoma, Kidawe & DDT 1053.2011 (UDSM) & $04^{\circ} 52^{\prime} 57^{\prime \prime S}, 029^{\circ} 48^{\prime} 41^{\prime \prime E}$ \\
\hline 2. & Afrocantharellus symoensii & DDT36 & Kisarawe, Kazimzumbwi & Tibuhwa 1036.2005 (UPS, UDSM) & $06^{\circ} 04^{\prime} 32^{\prime \prime S}, 039^{\circ} 15^{\prime} 56^{\prime \prime E}$ \\
\hline 3. & Cantharellus tomentosus & DDT68 & Morogoro, SUA Forest & Tibuhwa 1068.2007 (UPS, UDSM) & $06^{\circ} 52^{\prime} 34^{\prime \prime S}, 37^{\circ} 67^{\prime 2} 29^{\prime \prime} \mathrm{E}$ \\
\hline 4. & Cantharellus congolensis & DDT77 & Morogoro, SUA Forest & Tibuhwa 1077.2007 (UPS, UDSM) & $06^{\circ} 52^{\prime} 34^{\prime \prime S}, 37^{\circ} 67^{\prime} 29^{\prime \prime} \mathrm{E}$ \\
\hline 5. & Cantharellus cyanoxanthus & DDT06 & Tabora, Masange & Tibuhwa1006.2005 (UPS, UDSM) & $04^{\circ} 59^{\prime} 57^{\prime \prime S}, 032^{\circ} 40^{\prime} 20^{\prime \prime E}$ \\
\hline 6. & Cantharellus rufopunctatus & DDT10 & Tabora, Masange & Tibuhwa 1010.2004 (UPS, UDSM) & $04^{\circ} 59^{\prime} 22^{\prime \prime S}, 032^{\circ} 40^{\prime} 20^{\prime \prime} \mathrm{E}$ \\
\hline 7. & Cantharellus pseudocibarius & DDT70 & Morogoro, Ubenazomozi & Tibuhwa 1070.2007 & $06^{\circ} 55^{\prime} 11^{\prime \prime S}, 037^{\circ} 34^{\prime} 20^{\prime \prime E}$ \\
\hline
\end{tabular}

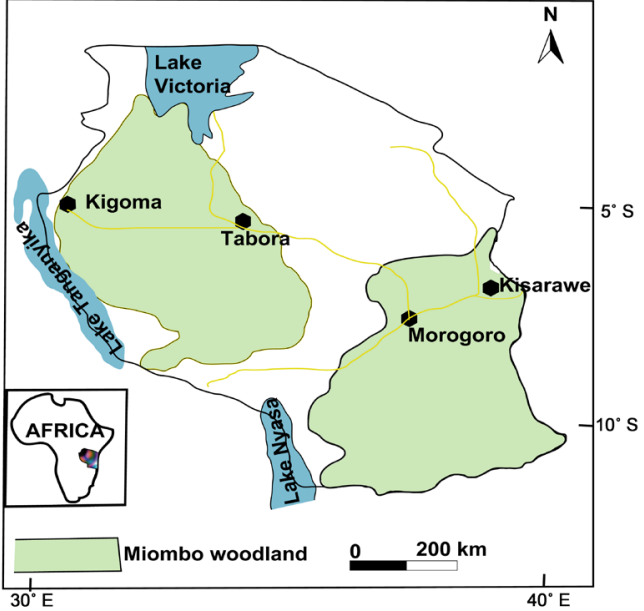

Figure 1. Map of Tanzania showing the study sites with miombo woodland.

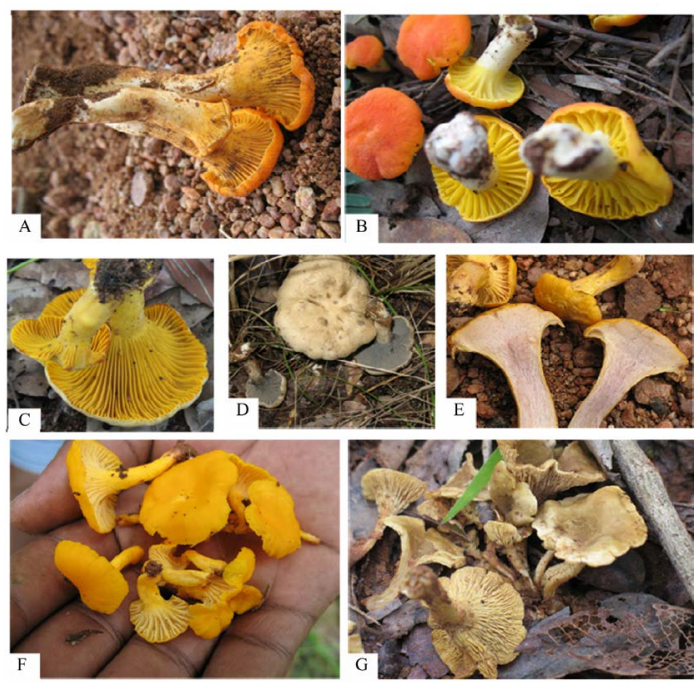

Figure 2. Studied taxa: (A) Afrocantahrellus splendens; (B) Afrocantharellus symoensii; (C) Cantharellus rufopunctatus; (D) Cantharellus congolensis; (E) Cantharellus cyanoxanthus; (F) Cantharellus pseudocibarius; (G) Cantharellus tomentosus (all photo taken by the author in the respective study sites detailed in Table 1). phenolic compounds, vitamin $\mathrm{C}, \beta$-carotene, lycopene and flavonoid) constituents of each extracts.

\subsubsection{Extracts Preparation}

Methanolic extractions were carried out using $25 \mathrm{~g}$ of the whole mushroom fruit body weighed using analytical balance at room temperature. The mushrooms were powdered in a motor using pestles and soaked in $250 \mathrm{ml}$ of methanol and extraction proceeded as explained in Jaita et al. [36]. It involved constant stirring of the material for 48 hrs then filtered using Whatman filter paper. The filtrates were evaporated to dryness at $40^{\circ} \mathrm{C}$ in a rotary evaporator under reduced pressure. The obtained concentrated extracts were stored in dark at $4^{\circ} \mathrm{C}$ until further analysis.

\subsubsection{Determination of Mushroom Extracts Yield}

The yields of evaporated dried extracts were obtained by gravimetric method. The percentage yield extracts were calculated based on dry weight as:

$$
\text { Yield }(\%)=\frac{\left(W_{1} \times 100\right)}{W_{2}}
$$

where $W_{1}=$ Weight of extract after methanol evaporation; $W_{2}=$ Weight of the extracted mushroom.

\subsubsection{Determination of Total Flavonoid}

The total flavonoid was determined with Aluminium chloride according to Jaita et al. [36] and Pitchaon et al. [37] using quercetin as standard. $1 \mathrm{ml}$ of each extract was diluted with $4.3 \mathrm{ml}$ of $80 \%$ aqueous ethanol containing $0.1 \mathrm{ml}$ of $10 \%$ Aluminum nitrate and $0.1 \mathrm{ml}$ of $1 \mathrm{Ma}-$ queous Potassium acetate. After 40 minutes incubation at room temperature, the absorbance was determined calorimetrically at $515 \mathrm{~nm}$ using the SAME spectrophotometer Uv-vis model 6305 Jenway UK. Total flavonoid concentration was calculated using quercetin standard calibration curve. Data were expressed as Rutin equivalent/100g of mushroom extracted. 


\subsubsection{Total Phenolic Contents Determination}

The total phenolic content in each mushroom extracts was determined using the Folin-Ciocalteu colorimetric method [38]. Each $0.1 \mathrm{gm}$ of extract was diluted with 5 $\mathrm{ml}$ of methanol. $200 \mu \mathrm{l}$ of the mushroom extract was transferred into a test tube then mixed thoroughly with 1 $\mathrm{ml}$ of Folin-Ciocalteau reagent. After $3 \mathrm{~min}, 0.8 \mathrm{ml}$ of $7.5 \%(\mathrm{w} / \mathrm{v})$ sodium carbonate was added to the mixture. The mixture was agitated for further 30 minutes in the dark and centrifuged at $3300 \mathrm{~g}$ for 5 minutes. The absorbance of mushroom extract and prepared blank were measured at $515 \mathrm{~nm}$ using spectrophotometer (Uv-vis model 6305 Jenway UK). The total phenolic content in the mushroom extract was expressed as milligram of gallic acid equivalent per $100 \mathrm{~g}$ weight of mushroom using the linear equation obtained from standard gallic acid calibration curve.

\subsection{5. $\beta$-Carotene and Lycopene Antioxidant Activity Assays}

The assay was carried out according to the method of Nagata and Yamashita [39]. The mushroom extract (100 mg) was shaken with $10 \mathrm{ml}$ of Acetone-hexane mixture (92:3) for 1 minute and filtered through Whatman number 4 filter paper. The absorbance of the filtrate was measured at 453, 505 and $663 \mathrm{~nm}$. The $\beta$-carotene and Lycopene content were calculated as:

$$
\begin{aligned}
\text { Lycopene mg/100mg }= & 0.0458 A_{663}+0.372 A_{505} \\
& -0.0806 A_{453} \\
\beta \text {-carotene mg/100mg }= & 0.216 A_{663}-0.304 A_{505} \\
& +0.452 A_{453}
\end{aligned}
$$

\subsubsection{Determination of Vitamin C}

The vitamin $\mathrm{C}$ content was determined titrametrically using 2.6 Dichloropheno Indophenol methods. Known weight of grounded sample was mixed with $25 \mathrm{ml}$ of $5 \%$ metaphosphoric acid solution and shaken for $30 \mathrm{~min}$. The mixture was then filtered through Whatman no 42 filter paper using suction pump. $10 \mathrm{ml}$ was pipetted from the extract in $250 \mathrm{ml}$ conical flask and titrated against $0.025 \%$ of 2.6 Dichlorophenol Indophenol reagents. The amount of vitamin $\mathrm{C}$ in each extract was calculated from the equation:

$$
\text { mg of ascorbic acid per } 100 \mathrm{~g}=\frac{A \times I \times V_{1} \times 100}{V_{2} \times W}
$$

where, $A=$ quantity of ascorbic acid (mg) reacting with 1 $\mathrm{ml}$ of 2.6 indophenol;

$I=$ volume of indophenol (in $\mathrm{ml}$ ) required for the completion for the titration with extract;

$V_{1}=$ total volume of extract;
$V_{2}=$ volume of extract used for each titration;

$W=$ weight of the mushroom sample extracted.

\subsubsection{DPPH Free Radical Scavenging Activity Assays} The qualitative assays were performed according to the method of Masuda et al. [40], Jaita et al. [36]. A series of extracts to methanol $\left(1: 10-1: 10^{5}\right)$ were prepared. Ascorbic acid was used as a standard control. A measure of 1 $\mathrm{ml}$ of the extract was mixed with $1 \mathrm{ml}$ of $0.4 \mathrm{mmol}^{-1} \mathrm{me}-$ thanolic solutions containing 1:1-diphenyl-2picryhydrazyl $(\mathrm{DPPH})$ radical that are very stable. Each free radical scavenging activity assay was done three times from the same extract in order to determine their reproducibility and standard deviation for the three readings were statistically determined. The mixture was left in the dark for $30 \mathrm{~min}$. and the absorbance measured at $515 \mathrm{~nm}$. The percentage of DPPH radical scavenging activity of each extract was determined at these five concentrations, within the range of dose response and was calculated as:

$$
\text { DPP radical scavenging activity }=\frac{A_{0}-\left(A_{1}-A_{s}\right)}{A_{0}} * 100
$$

where $A_{0}=$ absorbance of the control solution containing only DPPH;

$A_{1}=$ absorbance in the presence of mushroom extract in DPPH solution and;

$A_{s}=$ the absorbance of the sample extract solution without DPPH.

\subsection{Data Analysis}

The scavenging activities of crude extracts on DPPH radicals were carried out in triplicate and the results were expressed as means \pm standard errors. The $\mathrm{EC}_{50}$ value (total antioxidant necessary to decrease the initial DPPH radical concentration by $50 \%$ ) were obtained from the linear regression plots (Sigma Plot R 2001, SPSS) or calculated by substituting $50 \%$ for " $y$ " into the curve equation of scavenging activity against extracts concentrations.

\section{Results and Discussion}

From the analyzed extracts, all species posses organic compounds with antioxidant potentials in different concentrations and their intensity of antioxidant activities differed markedly within the species in their dry and fresh forms as well as between different species. While the fresh mushroom showed high vitamin $\mathrm{C}$ and lycopene, the phenolic compounds, $\beta$-carotene, and Flavonoid were much higher in dry forms of the same taxa (Figure 3). This indicates that some vitamin $\mathrm{C}$ and lycopene vanished during drying processes while sun-drying processes enhanced phenolic compounds $\beta$-carotene and 


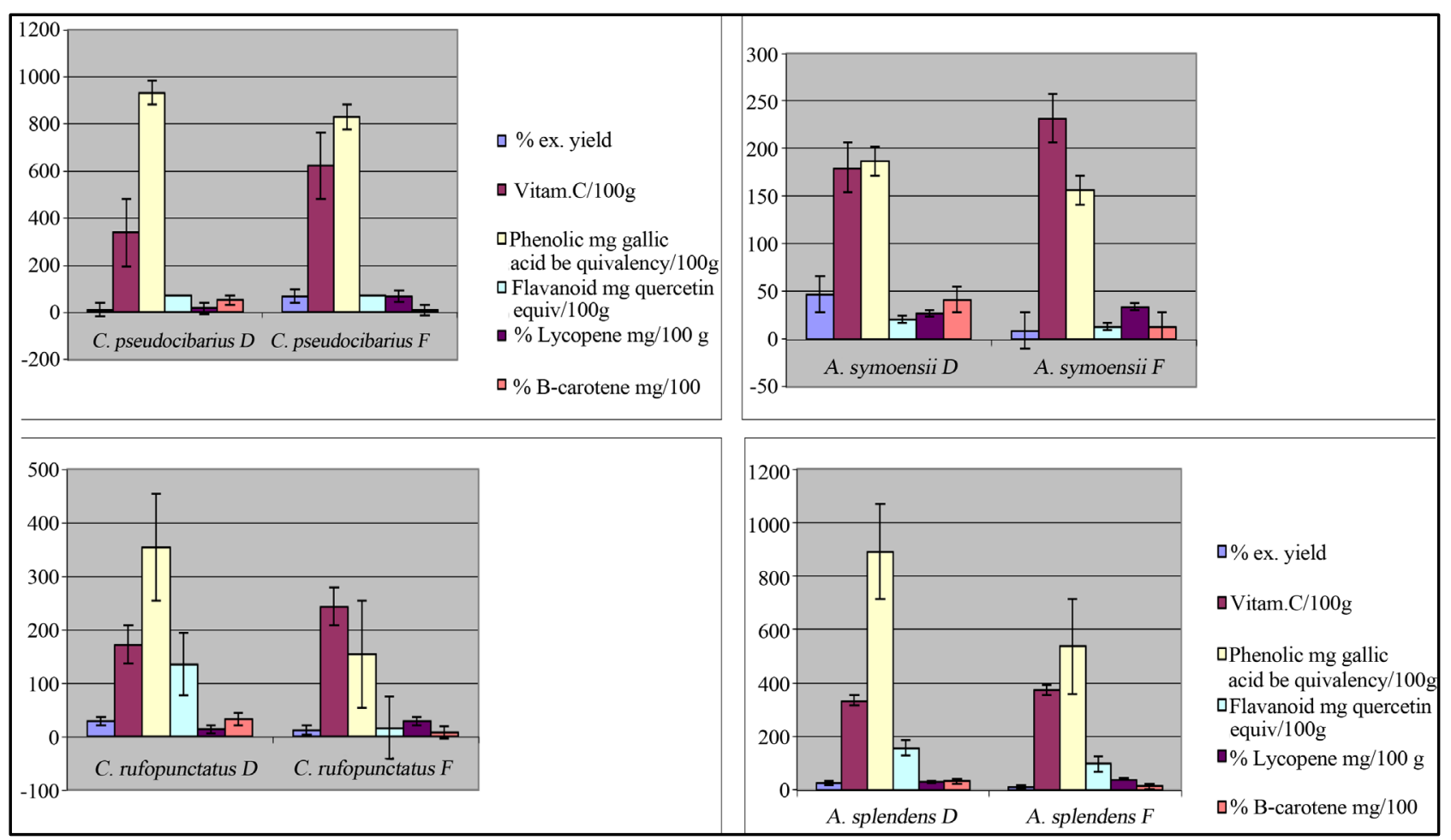

Figure 3. Comparison of antioxidant activities from fresh and dry mushrooms showing fresh mushroom having high vitamin $\mathrm{C}$ and lycopene while $\boldsymbol{\beta}$-carotene, flavonoid and phenolic compounds are higher in dry mushroom than in fresh.

flavonoid. In this study, sun-drying process that includes exposing the mushroom to the solar ultraviolet radiations has revealed to increase the amount of phenolic compounds among others, which correspond to the increased intensity of antioxidant activities. This finding is in agreement with the observation by Tibuhwa et al. (2012b) who also noted the $11 \%$ scavenging ability increase in Coprinus enhanced by sun drying process. The increase of antioxidant activities due to solar ultraviolet radiation exposure has been also observed in plants. A study by Masuda et al. [40], reported that seashore plants exhibiting strong antioxidant activity were associated with full sunlight exposures.

Although other antioxidant studies in mushroom shows low values of flavonoid $[14,41]$ to the extent of suggesting very sensitive equipment for its precision, it is interesting to find that the studied mushroom possess relative higher amount of flavonoid ranging from 13.07 to $155.16 \mathrm{mg}$ quercetin equivalent/100g in both forms. In the studied mushrooms, carotenoids (lycopene and $\beta$ carotene) were also high ranging from $12-68 \mathrm{mg} / 100 \mathrm{~g}$ in both forms. Lycopene is known to be the most efficient singlet oxygen quencher compared with a variety of carotenoids and a-tocopherol in vitro [42]. The study by Stahl et al. [43] shows that it is three times more efficient than $\beta$-carotene in preventing lipid peroxidation in multi lamellar liposomes. Lycopene has been also found to provide up to $35 \%$ protective effect against lung and prostate cancer with no associated risks [44]. The observed high amounts of antioxidant activity in the studied mushroom thus imply that, they can be used as food supplement or promoted into nutraceutics. Currently there are no established standard dietary intakes of phenolic compounds, however, Krebs-Smith et al. [45] reported that the American Cancer Society established $100 \mathrm{mg}$ per day of flavonoids as an adequate amount for the prevention of cancer and deteriorating illness. The mushrooms studied show that they have good amount of antioxidant activity. For example, the amount of flavonoid obtained in dry form of $A$. splendens and C. rufopunctatus were $155.16 \mathrm{mg} / 100 \mathrm{~g}$ and $134.31 \mathrm{mg} / 100 \mathrm{~g}$ which is even higher than the suggested daily intake by the American Cancer Society. Different research findings propose that mushroom rich in antioxidant activity play an important role in prevention of cancer [17,46-49]. A recent study by Masalu et al. [49] also revealed a new described species Cantharellus miomboensis species nov. from miombowoodland of Tanzania [50] to have the potential of inducing apoptosis an important stage in developing antitumor drugs. It is well known that excess free radicals may damage cellular lipids, proteins and DNA, affecting normal body function thus leading to various diseases including Cancer [51,52]. The established high antioxidant activities in these species envisage the pur- 
poseful promotion of eating wild mushrooms for the improved healthiness. Reducing power of any compound is often used as an indicator of its electron donating ability, which is an important mechanism for testing its ant oxidative ability. Dose dependency of the scavenging ability of hydroxyl radicals of the studied mushroom extracts was also investigated as a function of reducing power and presented in the order of their EC50 values. The result shows that the radical scavenging ability increases with increasing concentrations in all the samples (Table 2). However, fresh samples showed high hydroxyl radical scavenging activity compared to dry mushroom (Figure 4(b)).

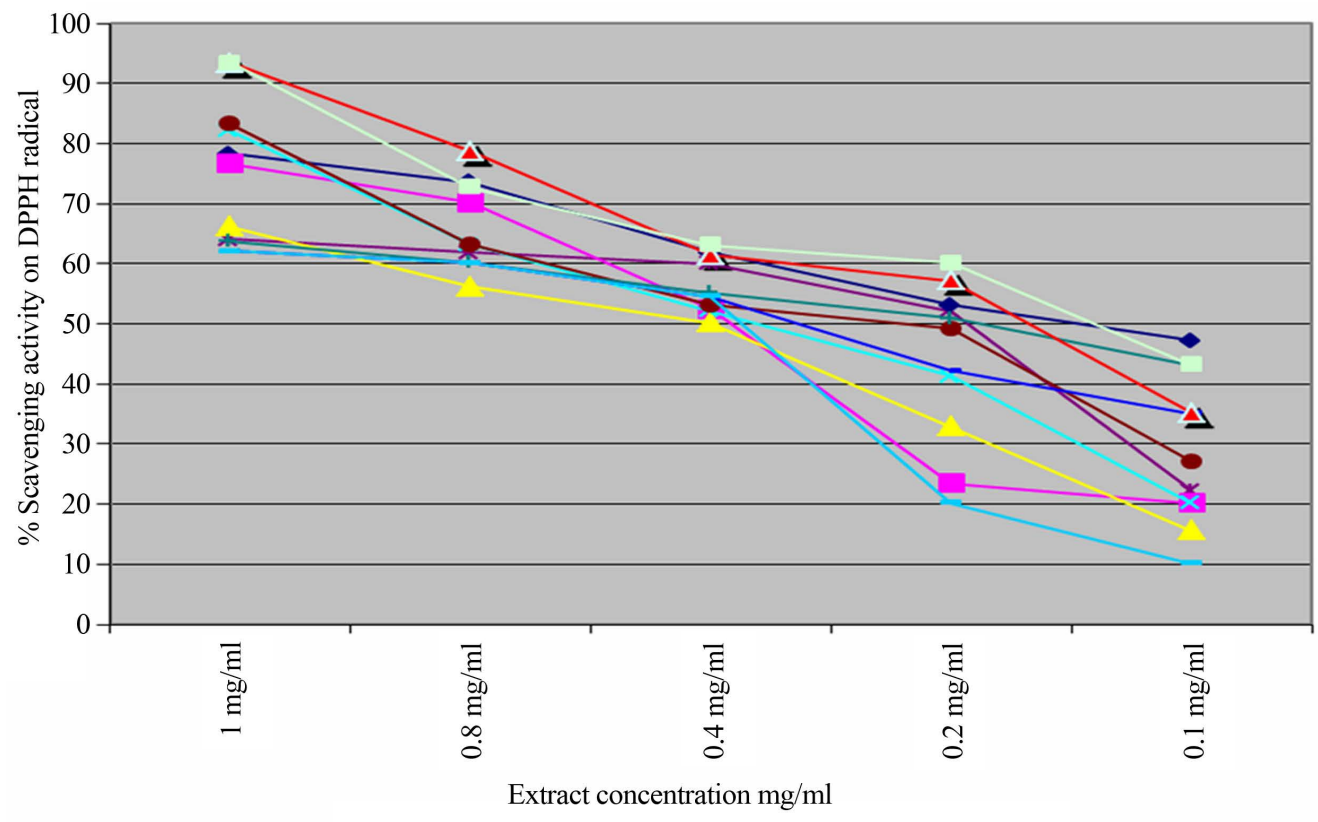

(a)

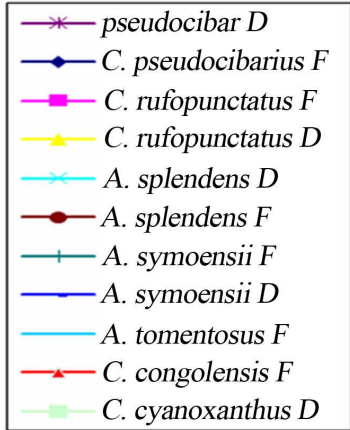

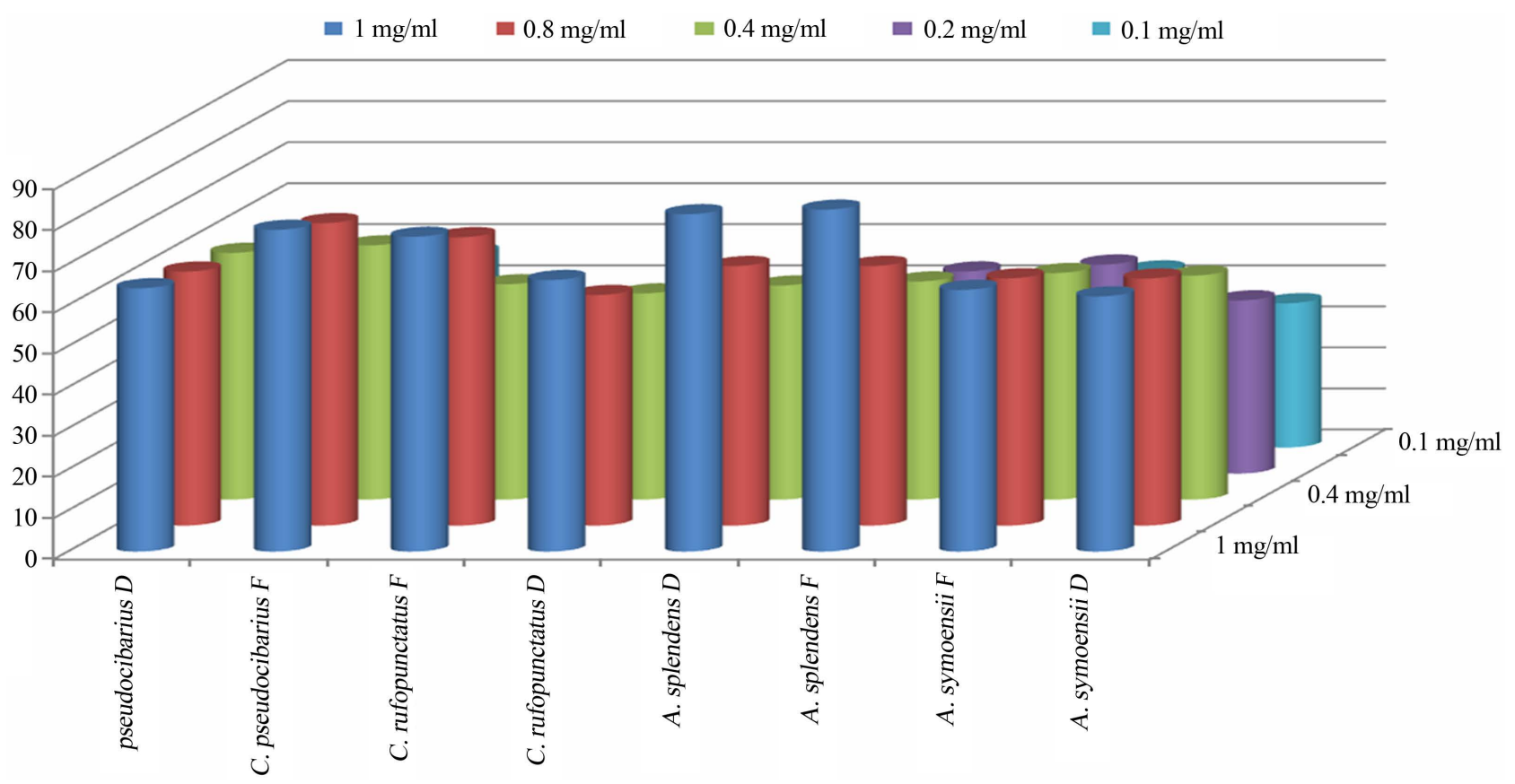

(b)

Figure 4. Percentage scavenging activity of (a) all studied species (b) comparing fresh and dry form only. 
Table 2. Average scavenging activity of crude extracts on DPPH radicals at different concentration in $\mathbf{m g} / \mathrm{ml}$.

\begin{tabular}{cccccc}
\hline Extracted sample & $\mathbf{1} \mathbf{~} \mathbf{g} / \mathbf{m l}$ & $\mathbf{0 . 8} \mathbf{~} \mathbf{g} / \mathbf{m l}$ & $\mathbf{0 . 4} \mathbf{~ m g} / \mathbf{m l}$ & $\mathbf{0 . 2} \mathbf{~ m g} / \mathbf{m l}$ & $\mathbf{0 . 1} \mathbf{~ m g} / \mathbf{m l}$ \\
\hline C. pseudocibarius F & $78.37 \pm 3.12$ & $61.87 \pm 7.82$ & $60.09 \pm 3.23$ & $53.13 \pm 8.64$ & $47.28 \pm 6.35$ \\
C. pseudocibarius D & $63.14 \pm 5.23$ & $73.66 \pm 8.41$ & $61.92 \pm 7.24$ & $52.14 \pm 5.32$ & $22.30 \pm 2.34$ \\
C. rufopunctatus D & $71.68 \pm 8.64$ & $71.68 \pm 3.85$ & $52.45 \pm 7.64$ & $32.90 \pm 6.43$ & $20.17 \pm 1.97$ \\
C. rufopunctatus F & $82.17 \pm 7.43$ & $70.23 \pm 4.65$ & $50.22 \pm 5.32$ & $43.15 \pm 3.57$ & $15.60 \pm 2.42$ \\
A. splendens D & $82.17 \pm 1.16$ & $56.16 \pm 5.32$ & $52.13 \pm 5.67$ & $41.34 \pm 4.48$ & $20.21 \pm 1.28$ \\
A. splendens F & $83.22 \pm 1.36$ & $63.21 \pm 9.42$ & $53.13 \pm 4.92$ & $49.24 \pm 3.98$ & $27.12 \pm 4.87$ \\
A. symoensii F & $63.73 \pm 2.26$ & $63.23 \pm 7.43$ & $55.18 \pm 6.67$ & $50.91 \pm 4.76$ & $43.13 \pm 3.98$ \\
A. symoensii D & $62.14 \pm 2.06$ & $60.22 \pm 2.32$ & $54.56 \pm 3.45$ & $42.18 \pm 3.23$ & $35.14 \pm 5.64$ \\
C. tomentosus F & $62.14 \pm 2.86$ & $60.16 \pm 2.69$ & $54.55 \pm 5.22$ & $20.16 \pm 8.76$ & $10.17 \pm 7.43$ \\
C. congolensis D & $94.14 \pm 3.64$ & $78.81 \pm 6.58$ & $61.49 \pm 5.41$ & $57.25 \pm 5.16$ & $35.16 \pm 2.33$ \\
C. cyanoxanthus D & $93.48 \pm 9.24$ & $72.79 \pm 8.72$ & $63.14 \pm 8.41$ & $60.15 \pm 7.62$ & $43.14 \pm 9.12$ \\
\hline
\end{tabular}

It was interesting to note a high variation of radical scavenging ability between different forms of the same species, but also between the two genera. For example, the variation of the radical scavenging ability in Afrocantharellus species increased by $0.86 \%$ and $0.99 \%$ for $A$. splendens and $A$. symoensii, respectively. The variation was however noticeable higher in Cantharellus species with fresh forms having higher values than their dry counterparts by $24.12 \%$ and $7.52 \%$ for C. pseudocibarius and C. rufopunctus, respectively (Table 2).

A fresh prepared DPPH solution was deep purple in colour which faded away as the DPPH free radicals were quenched and converted into a colourless product $(2,2$ diphenyl-1-hydrazine) resulting in absorbance decrease, thus the more rapidly the absorbance decreased the more effective was the antioxidant activity of the extracts. The highest activity was observed at the concentration of 1 $\mathrm{mg} / \mathrm{ml}$ and it was in the dry form of Cantharellus congolensis $(94.14 \mathrm{mg} / \mathrm{ml})$ although it missed the fresh form for comparison. The used Vitamin $\mathrm{C}$ as a positive control showed $\mathrm{EC}_{50}$ Value (mg equivalent Vitamin-C/mg dry weight extract) of 1 . None of the samples evaluated here showed activity as strong as the standard antioxidant Vitamin-C. Others comparing their activity in $\mathrm{mg} / \mathrm{ml}$ of fresh against dry form were in the order of Afrocantharellus splendens (83.22 fresh vs $82.17 \mathrm{dry})>(82.17$ fresh vs 71.68 dry) for Cantharellus rufopunctatus, > (78.37 fresh vs 63.14 dry) for Cantharellus pseudocibarius and $>63.73$ fresh vs 62.14 dry for Afrocantharellus symoensii. The plotted graph of scavenging activity against different concentration of the extracts shows that the antioxidant activity increases with increasing concentration, the finding that has also been reported by Tibuhwa [14] and Banerjee [53]. The obtained extract radical scaveng- ing effect was found to be positively correlated with the amount of total phenolic compounds $(r=0.8983)$. In this correlation, the higher the phenolic content the best the scavenging power. This result has been also observed in other studies including Wong and Chye [21], Filipa et al. [54], Tibuhwa [14]. In this study this fact has been also well revealed. For example, Species C. pseudocibarius was observed to have high phenolic compounds of $933.31 \mathrm{mg} / 100 \mathrm{~g}$ which corresponded with high scavenging ability of less than $0.14 \mathrm{mg} / \mathrm{ml}$ compared to species $C$. rufopunctatus which possessed least phenolic compound of $153.86 \mathrm{mg} / 100 \mathrm{~g}$ and exhibited lowest scavenging ability of $0.4 \mathrm{mg} / \mathrm{ml}$.

Interestingly, the total antioxidant necessary to decrease the initial DPPH radical concentration by 50\% differed markedly with different forms and between the species. For example the highest ability was observed in both fresh and dry forms of Cantharellus pseudocibarius $\left(\mathrm{EC}_{50}<0.14 \mathrm{mg} / \mathrm{ml}\right.$ and $\left.\mathrm{EC}_{50}<0.175 \mathrm{mg} / \mathrm{ml}\right)$ followed by fresh and dry forms of Afrocantharellus symoensii $\left(\mathrm{EC}_{50}=0.2 \mathrm{mg} / \mathrm{ml}\right.$ and $\left.\mathrm{EC}_{50}<0.35 \mathrm{mg} / \mathrm{ml}\right)$ while the least ability $\left(\mathrm{EC}_{50}=0.4 \mathrm{mg} / \mathrm{ml}\right)$ was from dry form of Cantharellus rufopunctatus (Figure 4(b)). These results reveal that the studied mushrooms have high scavenging ability in both forms compared to abilities observed in well-known medicinal plants such as Ardisia japonica $\mathrm{EC}_{50}=12.72 \mu \mathrm{g} / \mathrm{ml}$ Ardisia conyzoides $\mathrm{EC}_{50}=15.19$ $\mu \mathrm{g} / \mathrm{ml}$ and Cocculus hirsutus $\mathrm{EC}_{50}=10.68 \mu \mathrm{g} / \mathrm{ml}$ [55].

Human beings are among aerobic organisms; our body constantly produced free radicals during normal cellular metabolism that sometime exceed the natural endogenous defense mechanisms to eliminate them. The studied mushrooms have been found to possess potential antioxidants in high amount. Supplying our body with natu- 
ral products with antioxidant activity like these mushrooms will help and boost the body's endogenous defense system.

\section{Conclusion}

All the seven Afrocantharellus and Cantharellus mushroom species showed a significant amount of antioxidant activity in their different forms along with higher amount of total phenolics, flavonoids, $\beta$-carotene and high ability to scavenge DPPH radical. These findings indicate that these mushrooms are valuable sources of antioxidant thus utilizing them as potential sources of natural antioxidants. They should thus, be sought to be promoted into potential nutraceutics. This is the first study on antioxidant activity of wild edible Afrocantharellus and Cantharellus mushrooms from miombo woodlands of Tanzania. The study, therefore, recommends for fractionation study on the observed high phenolic compounds from these mushrooms in order to identify them and establish their mechanism of action.

\section{Acknowledgements}

The author is thankful to the Sida-SAREC, through the International Science Programme at Uppsala University and the Molecular Biology project of the University of Dar es Salaam, for financial support. The author is also indebted to Mr. Charles Kweyunga of Botany Department University of Dar salaam for helping with the analysis.

\section{REFERENCES}

[1] B. Halliwell and J. M. C. Gutteridge, "Oxyegen Toxicity, Oxygen Radicals, Transition Metals and Disease," Biochemistry Journal, Vol. 219, 1984, pp. 1-14.

[2] F. Navarro-Ocaña, A. Medrano-Martínes and A. RuizTéran, “Antioxidant and Free Radical Scavenging Activities of Plant Extracts Used in Traditional Medicine in Mexico," African Journal of Biotechnology, Vol. 7, No. 12, 2008, pp. 1886-1893.

[3] T. Mizuno, "The Extraction and Development of Antitumoractive Polysaccharides from Medicinal Mushrooms in Japan (Review)," International Journal of Medicinal Mushrooms, Vol. 1, No. 1, 1999, pp. 9-30.

[4] F. Batool, M. S. Sabir, J. B. T. Rocha, A. S. Shah, S. Z. Saify and D. S. Ahmed, "Evaluation of Antioxidant and Free Radicalscavenging Activities of Fruit Extract from Zanthoxylum alatum: A Commonly Used Spice from Pakistan,” Pakistan Journal of Botany, Vol. 42, No. 6, 2010, pp. 4299-4311.

[5] C. D. Dillard and J. B. German, "Phytochemicals: Nutraceuticals and Human Health," Journal of the Science of Food and Agriculture, Vol. 80, No. 12, 2000, pp. 17441756. http://dx.doi.org/10.1002/1097-0010(20000915)80:12<17 44::AID-JSFA725>3.0.CO;2-W

[6] S. Y. Wang and H. S. Linn, "Antioxidant Activity in Fruits and Leaves of Blackberry, Raspberry, and Strawberry Varies with Cultivar and Developmental Stage," Journal of the Science of Food and Agriculture, Vol. 48, No. 2, 2000, pp. 140-146. http://dx.doi.org/10.1021/jf9908345

[7] Medić-Sarić, M. Boji, V. Rastija and J. Cvek, "Polyphenolic Profiling of Croatian Propolis and Wine,” Food Technology and Biotechnology, Vol. 51, No. 2, 2013, pp. 159-170.

[8] C. Ramesh and M. G. Pattar, “Antimicrobial Properties, Antioxidant Activity and Bioactive Compounds from Six Wild Edible Mushrooms of Western Ghats of Karnataka, India,” Pharmacognosy Research, Vol. 2, No. 2, 2010, pp. 107-112. http://dx.doi.org/10.4103/0974-8490.62953

[9] R. Rodrigo and C. Bosco, "Oxidative Stress and Protective Effects of Poly Phenols: Comparative Studies in Human and Rodent Kidney: A Review," Comparative Biochemistry and Physiology, Vol. 142, No. 2, 2006, pp. 317-327.

[10] G. Burgosa, W. Amorosa, L. Muñoaa, P. Sosaa, E. Cayhuallaa, C. Sancheza, C. Díazb and M. Bonierbalea, "Total Phenolic, Total Anthocyanin and Phenolic Acid Concentrations and Antioxidant Activity of Purple-Fleshed Potatoes as Affected by Boiling," Journal of Food Composition and Analysis, Vol. 30, No. 1, 2013, pp. 6-12. http://dx.doi.org/10.1016/j.jfca.2012.12.001

[11] N. Jose, T. A. Ajith and K. K. Janardhanan, “Antioxidant, Anti-Inflammatory and Antitumor Activities of Culinarymedicinal Mushroom Pleurotus pulmonarius (Fr.) Quel. (Agaricomycetideae)," International Journal of Medicinal Mushrooms, Vol. 4, No. 4, 2002, pp. 329-335. http://dx.doi.org/10.1615/IntJMedMushr.v4.i4.60

[12] S. Jones and K. K. Janardhanan, "Antioxidant and Antitumor Activity of Ganoderma lucidum (Curt.: Fr.) P. Karst.-Reishi (Aphyllophoromycetideae) from South India,” International Journal of Medicinal Mushrooms, Vol. 2, No. 3, 2008, pp. 195-200.

[13] D. D. Tibuhwa, “Antiradical and Antioxidant Activities of Methanolic Extracts of Indigenous Termitarian Mushroom from Tanzania," Food Science Quality and Management, Vol. 7, 2012, pp. 13-23.

[14] D. D. Tibuhwa, S. L. Lyantagaye and A. M. Mshandete, "Effect of Different Post-Harvest Treatments on Nutritive and Antioxidant Activities of Edible Coprinus cinereus (Schaeff.) S. Gray from Tanzania,” International Journal of Research in Biological Sciences Vol. 2, No. 4, 2012, pp. 150-156.

[15] A. V. Aletor, "Compositional Studies on Edible Tropical Species of Mushrooms," Food Chemistry, Vol. 54, No. 3, 1995, pp. 265-268. http://dx.doi.org/10.1016/0308-8146(95)00044-J

[16] T. Yaltirak, B. Aslim, S. Ozturk and H. Alli, "Antimicrobial and Antioxidant Activities of Russula delica Fr," Food and Chemical Toxicology, Vol. 47, No. 8, 2009, pp. 2052-2056. http://dx.doi.org/10.1016/j.fct.2009.05.029 
[17] W. Feng, J. Naga and T. Ikekawa, “A Clinical Pilot Study of EEM for Advanced Cancer Treatment with EEM for Improvement of Cachexia and Immune Function Compared with MPA,” Biotherapy, Vol. 15, 2001, pp. 691696.

[18] R. Chang, "Functional Properties of Edible Mushrooms," Nutrition Review, Vol. 54, No. 11, 1996, pp. 91-93. http://dx.doi.org/10.1111/j.1753-4887.1996.tb03825.x

[19] G. M. Halpern and A. H. Miller, "Medicinal Mushrooms," Evans M. and Company Inc., New York, 2000, pp. 59-74.

[20] S. P. Wasser, "Medicinal Mushrooms as a Source of Antitumor and Immunomodulating Polysaccharides," Applied Microbiology and Biotechnology, Vol. 60, No. 3, 2002, pp. 258-274. http://dx.doi.org/10.1007/s00253-002-1076-7

[21] J. Y. Wong and F. Y. Chye, "Antioxidant Properties of Selected Tropical Wild Edible Mushrooms," Journal of Food Composition and Analysis, Vol. 22, No. 4, 2009, pp. 269-277. http://dx.doi.org/10.1016/j.jfca.2008.11.021

[22] M. Härkönen, T. Saarimäki and L. Mwasumbi, "Edible Mushrooms of Tanzania,” Karstenia Helsinki, Vol. 35, 1995, p. 92.

[23] M. Härkönen, T. Niemelä and L. Mwasumbi, "Tanzanian Mushrooms. Edible, Harmful and Other Fungi,” Botanical Museum, Finish Museum of Natural History, Helsinki, 2003, p. 200.

[24] D. D. Tibuhwa, "Diversity of Macrofungi at the University of Dar es Salaam Mlimani Main Campus in Tanzania," International Journal of Biodiversity and Conservation, Vol. 3, No. 11, 2011, pp. 540-550.

[25] D. D. Tibuhwa, "Wild Mushroom-An Underutilized Resource for Healthy Food and Income Generation: Experience from Tanzania Rural Areas," Journal of Ethnobiolgy and Ethnomedicine, Vol. 9, No. 49, 2013, pp. 1-13.

[26] D. D. Tibuhwa, M. Nyawira, C. W. Masiga, C. Mugoya and M. Muchai, "An Inventory of Macro-Fungi and Their Diversity in the Serengeti-Masai Mara Ecosystem, Tanzania and Kenya,” Journal of Biological Sciences, Vol. 11, No. 6, 2011, pp. 399-410. http://dx.doi.org/10.3923/jbs.2011.399.410

[27] D. D. Tibuhwa, S. Savić, T. Tibell and A. K. Kivaisi, "Afrocantharellus gen. nov. Is Part of a Rich Diversity of African Cantharellaceae,” IMA Fungus, Vol. 3, No. 1, 2012, pp. 25-39. http://dx.doi.org/10.5598/imafungus.2012.03.01.04

[28] B. Campbell, P. Frost and N. Byron, "Miombo Woodlands and Their Use: Overview and Key Issues,” In: B. Campbell, Ed., The Miombo in Transition: Woodlands and Welfare in Africa, CFIOR, Bogor, 1996, pp. 1-10.

[29] N. Caglarirmak, K. Unal and S. Otles, "Nutritional Value of Edible Wild Mushrooms Collected from the Black Sea Region of Turkey,” Micologia Aplicada International, Vol. 14, No. 1, 2002, pp. 1-5.

[30] A. Colak, Y. Kolcuoğlu, E. Sesli and Ö. Dalman, "Biochemical Composition of Some Turkish Fungi," Asian Journal of Chemistry, Vol. 19, No. 1, 2007, pp. 21932199.
[31] A. H. Wani, R. H. Boda, T. Nisa and L. A. Peer, "Potential Antioxidant Activity of Some Mushrooms Growing in Kashmir Valley,” Mycopath, Vol. 8, No. 2, 2010, pp. 7175.

[32] D. Kumari, M. S. Reddy and R. C. Upadhyay, "Antioxidant Activity of Three Species of Wild Mushroom Genus Cantharellus Collected from North-Western Himalaya, India,” International Journal of Agriculture Biology, Vol 13, No. 3, 2011, pp. 415-418.

[33] D. Arora, "Mushrooms Demystified: A Comprehensive Guide to the Fleshy Fungi," Ten Speed Press, Berkeley 1986, p. 959.

[34] P. M. Kirk, P. F. Cannon, J. C. David and J. A. Stalfers, "Ainsworth and Bisby's Dictionary of the Fungi," 9th Edition, CABI Publishing, 2001, Electronic version. htpp://www.speciesfungorum.org/AuthorsoffungalNames htm

[35] J. D. Lodge, F. J. Ammirati, E. T. O’Dell and M. J. Mueller, "Collecting and Describing Macrofungi," In: M. G. Mueller, F. G. Bills and S. M. Foster, Eds., Biodiversity of Fungi: Inventory and Monitoring Methods, Elsevier Academic Press, San Diego, 2004, pp. 128-158.

[36] P. Jaita, G. Sourav, A. T. Saifa and A. Krishnendu, "In Vitro Free Radical Scavenging Activity of Wild Edible Mushroom, Pleurotus squarrosulus (Mont.) Singer," Indian Journal of Experimental Biology, Vol. 47, No. 12, 2010, pp. 12101218.

[37] M. Pitchaon, S. Maitree and P. Rungnaphar, “Assessment of Phenolic Content and Free Radical-Scavenging Capacity of Some Thai Indigenous Plants,” Food Chemistry, Vol. 100, No. 4, 2007, pp. 1409-1418. http://dx.doi.org/10.1016/j.foodchem.2005.11.032

[38] V. L. Singleton, R. Orthofer and R. Lamuela-Raventós, "Analysis of Total Phenols and Other Oxidation Substrates and Antioxidants by Means of Folin-Cicalteu Reagent," Methods in Enzymology, Vol. 299, 1999, pp. 152-178. http://dx.doi.org/10.1016/S0076-6879(99)99017-1

[39] M. Nagata and I. Yamashita, "Simple Method for Simultaneous Determination of Chlorophyll and Carotenoids in Tomato Fruit," Nippon Shokuhin Kogyo Gakkaish, Vol. 39, No. 10, 1992, pp. 925-928. http://dx.doi.org/10.3136/nskkk1962.39.925

[40] T. Masuda, S. Yonemori, Y. Oyama, Y. Takeda, T. Tanaka, T. Andoh, A. Shinohara and M. Nakata, "Evaluation of the Antioxidant of Environmental Plants: Activity of the Leaf Extracts from Seashore Plants," Journal of Agricultural and Food Chemistry, Vol. 47, No. 4, 1999, pp. 1749-1754. http://dx.doi.org/10.1021/jf980864s

[41] A. E. S. S. Carvajal, et al., "Bioactives of Fruiting Bodies and Submerged Culture Mycelia of Agaricus brasiliensis (A. blazei) and Their Antioxidant Properties," LWT-Food Science and Technology, Vol. 46, No. 2, 2012, pp. 493499.

[42] P. Di Mascio, S. Kaiser and H. Sies, "Lycopene as the Most Efficient Biological Carotenoid Singlet Oxygen Quencher," Archives of Biochemistry and Biophysics, Vol. 274, No. 2, 1989, pp. 532-538. http://dx.doi.org/10.1016/0003-9861(89)90467-0 
[43] W. Stahl, A. Junghans, B. de Boer, E. S. Driomina, K. Briviba and H. Sies, "Carotene Mixture Protects Multilamellar Liposomes against Oxidative Damage: Synergistic Effects of Lycopene and Lutein,” FEBS Letters, Vol. 427, No. 2, 1998, pp. 305-308. http://dx.doi.org/10.1016/S0014-5793(98)00434-7

[44] L. Arab, S. Steck-Scott and P. Bowen, "Participation of Lycopene and Beta-Carotene in Carcinogenesis: Defenders, Aggressors, or Passive Bystanders?” Epidemiologic Reviews, Vol. 23, No. 2, 2001, pp. 211-230. http://dx.doi.org/10.1093/oxfordjournals.epirev.a000803

[45] S. M. Krebs-Smith, D. A. Cook, A. F. Subar, L. Cleveland and J. Friday, "US Adults' Fruit and Vegetable Intakes, 1989 to 1991: A Revised Baseline for the Healthy People 2000 Objective," American Journal of Public Health, Vol. 85, No. 12, 2000, pp. 1623-1629. http://dx.doi.org/10.2105/AJPH.85.12.1623

[46] N. Bahl, "Medicinal Value of Edible Fungi," Proceedings of the International Conference on Science and Cultivation Technology of Edible Fungi. Indian Mushroom Science, Vol. 2, 1983, pp. 203-209.

[47] P. M. Kidd, "The Use of Mushroom Glucans and Proteoglycans in Cancer Therapy," Alternative Medicine Review, Vol. 5, No. 1, 2000, pp. 4-27.

[48] S. P. Wasser and A. L. Weig, "Therapeutic Effects of Substances Occuring in Higher Basidiomycete Mushrooms: A Modern Perspective," Critical Review in Immunology, Vol. 19, No. 1, 1999, pp. 65-96.

[49] R. Masalu, K. M. Hosea, M. Meyer, S. Lyantagaye and S. Kanyanda, "Induction of Early Apoptosis and Reactive Oxygen Species (ROS) Production by Tanzanian Basi- diomycete (Cantharellus miomboensis),” International Journal of Biological and Chemical Sciences, Vol. 4, No. 4, 2010, pp. 825-833.

[50] D. D. Tibuhwa, "Taxonomic Studies on Cantharellus (Mushrooms) from the Miombo Woodlands of Tanzania,” Ph.D. Thesis, University of Dar es Salaam, Tanzania, 2009.

[51] J. L. Mau, H. C. Lin and C. C. Chen, "Antioxidant Properties of Several Medicinal Mushrooms,” Journal of Agricultural and Food Chemistry, Vol. 50, No. 21, 2002, pp. 6072-6077. http://dx.doi.org/10.1021/jf0201273

[52] I. C. F. Ferreira, L. Barros and R. M. V. Abreu, "Antioxidants in Wild Mushrooms," Current Medicinal Chemistry, Vol. 16. No. 12, 2009, pp. 1543-1560. http://dx.doi.org/10.2174/092986709787909587

[53] S. Banerjee, K. R. Sanjay, S. Chethan and N. G. Malleshi, "Finger Millet (Eleusine coracana) Polyphenols: Investigation of Their Antioxidant Capacity and Antimicrobial Activity," African Journal of Food Science, Vol. 6, No. 13, 2012, pp. 362-374. http://dx.doi.org/10.5897/AJFS12.031

[54] S. R. Filipa, C. F. R. F. Isabel, L. Barros and A. Martins, "A Comparative Study of Tocopherols Composition and Antioxidant Properties of in Vivo and in Vitro Ectomycorrhizal Fungi," Food Science and Technology, Vol. 44, No. 4, 2011, pp. 820-824.

[55] M. M. Mon, S. S. Maw and Z. K. Oo, "Quantitative Determination of Free Radical Scavenging Activity and Antitumor Activity of Some Myanmar Herbal Plants,” World Academy of Science, Engineering and Technology, Vol. 51, 2011, pp. 523-529. 